\title{
Comparison of Primary Afferent and Glutamate Excitation of Neurons in the Mammalian Spinal Dorsal Horn
}

\author{
Stephen P. Schneider and Edward R. Perl \\ Department of Physiology, University of North Carolina at Chapel Hill, Chapel Hill, North Carolina 27514
}

The actions of L-glutamate and agonists, agents blocking their membrane receptors and dorsal root afferent volleys, were compared on intracellularly recorded neuronal activity in an in vitro horizontal slice preparation of the hamster spinal dorsal horn. Bath-applied L-glutamate or L-aspartate ( $\leq 1$ $\mathrm{mm}$ ) rapidly depolarized and excited less than a third of the dorsal horn neurons sampled. Bathing solutions containing low $\mathrm{Ca}^{2+}$ eliminated synaptic transmission in the slices but failed to block the excitatory effects of L-glutamate for the majority of the neurons tested. $\boldsymbol{N}$-Acetylaspartylglutamate had no effect on dorsal horn neurons at concentrations up to $1 \mathrm{~mm}$.

Neurons excited by L-glutamate were most commonly located in the superficial dorsal horn (laminae l and II). Neurons insensitive to L-glutamate were more broadly distributed, with a number being located in laminae III-V.

Kynurenic acid, 2-amino-4-phosphonobutyric acid, and 2,3piperidine dicarboxylic acid selectively antagonized rapid, short-lasting synaptic components of the dorsal cord potentials. Kynurenic acid reversibly antagonized intracellularly recorded L-glutamate-induced excitation, spontaneous synaptic potentials, and fast synaptic potentials evoked by dorsal root volleys. Compounds with strong antagonist actions at the NMDA receptor, 2-amino-5-phosphonovaleric acid and $D$ - $\alpha$-aminoadipic acid, were much less effective in suppressing the effects of L-glutamate or in blocking synaptic potentials.

We conclude that a subset of spinal neurons directly excited by dorsal root fibers have excitatory membrane receptors activated by $L$-glutamate. This conclusion is consistent with the concept that L-glutamate or a substance binding to the receptors it activates is released from the central terminals of some primary afferent fibers and mediates fast synaptic transmission from them to certain spinal neurons in the dorsal horn.

The distribution, uptake, and release of L-glutamate in regions of the spinal cord known to receive terminations from afferent fibers (Graham et al., 1967; Johnson and Aprison, 1970; Balcar and Johnston, 1972; Roberts, 1974) have made it a candidate for chemical transmission at synapses of the central terminals

\footnotetext{
Received June 3, 1987; revised Oct. 15, 1987; accepted Oct. 19, 1987.

We are grateful to Ms. Sherry Derr for considerable assistance in preparing the manuscript. Supported by Grant NS10321 from the NINCDS of the U.S. Public Health Service. S.P.S. was a recipient of NIH National Research Service Award NS07317.

Correspondence should be addressed to Dr. Schneider at the above address.

Copyright (C) 1988 Society for Neuroscience $0270-6474 / 88 / 062062-12 \$ 02.00 / 0$
}

of primary sensory neurons (see reviews by Curtis and Johnston, 1974; Puil, 1981). With few exceptions, previous reports have suggested an absence of selectivity in the excitatory action of L-glutamate on spinal and medullary neurons (Curtis et al., 1960; Zieglgansberger and Herz, 1971; Zieglgansberger and Puil, 1973; Galindo et al., 1977; Hill and Salt, 1982), supporting the contention that L-glutamate is a nonspecific, universal excitant (Curtis et al., 1960). However, there is evidence for a selective concentration of glutamate-related compounds in smaller dorsal root ganglion (DRG) neurons. For example, Cangro et al. (1985a) reported that phosphate-dependent glutaminase, an enzyme of possible importance for the synthesis of releasable pools of L-glulamate (Kvamme, 1983), is elevated only in a subpopulation of small DRG cells. Also, small DRG cells accumulate 6 times more glutamine, a precursor in the synthesis of L-glutamate, than larger DRG neurons (Duce and Keen, 1983).

The mammalian superficial dorsal horn is known to receive terminations principally from fine-diameter, primary afferent axons (Light and Perl, 1979). Our earlier observations on extracellularly recorded activity in an in vitro preparation indicated that L-glutamate and L-aspartate preferentially excited neurons located in this region compared to deeper layers (Schneider and Perl, 1985a). We report here a comparison of the effects of blocking compounds and other manipulations on the primary afferent and L-glutamate-related excitation of dorsal horn neurons in intracellular recordings made in the same kind of preparation. Preliminary results have been presented elsewhere (Schneider and Perl, 1985b).

\section{Materials and Methods}

Preparation of tissue. Slices of lumbosacral spinal cord were obtained from 3- to 4-week-old, free-ranging, male Syrian hamsters weighing 35$55 \mathrm{gm}$ by a modification of the procedure described by Bagust et al. (1982). Under anesthesia with urethane $(1.5 \mathrm{mg} / \mathrm{gm})$, the animals were cooled to $23-25^{\circ} \mathrm{C}$ by partial immersion in ice water. The vertebral column from midthorax to sacrum was removed and placed in chilled $\left(3-8^{\circ} \mathrm{C}\right)$ artificial cerebrospinal fluid (ACSF) containing $125 \mathrm{~mm} \mathrm{NaCl}$, $5 \mathrm{mM} \mathrm{KCl}, 2.5 \mathrm{mM} \mathrm{CaCl}_{2}, 1.5 \mathrm{mM} \mathrm{MgSO}_{4}, 1.25 \mathrm{mM} \mathrm{NaH}_{2} \mathrm{PO}_{4}, 24 \mathrm{mM}$ $\mathrm{NaHCO}_{3}$, and $10 \mathrm{~mm}$ glucose at pH 7.4 equilibrated with $95 \% \mathrm{O}_{2} / 5 \%$ $\mathrm{CO}_{2}$. The spinal cord was exposed by cutting away the vertebrae on each side, freed from bone and muscle, and a single, horizontal knife cut was made by hand with a fragment of razor blade parallel to and midway between the dorsal and ventral surfaces. In less than 3 min these procedures produced a slice of dorsal spinal cord approximately $400-600 \mu \mathrm{m}$ thick with dorsal roots and sensory ganglia attached.

The slice was placed together with dorsal rootlets and sensory ganglia onto a stiff, nylon grid suspended over a layer of Sylgard (Dow Corning) in the recording chamber (volume, $1.5 \mathrm{ml}$ ), and all tissue was superfused with oxygenated $\operatorname{ACSF}(12-16 \mathrm{ml} / \mathrm{min})$ at room temperature $\left(23-27^{\circ} \mathrm{C}\right)$. A singlc, lumbar dorsal rootlet was isolated, placed onto platinum wire electrodes in an adjacent well connected to the recording chamber (Fig. $1 A)$ and covered with a mixture of petroleum jelly and mineral oil. 
A

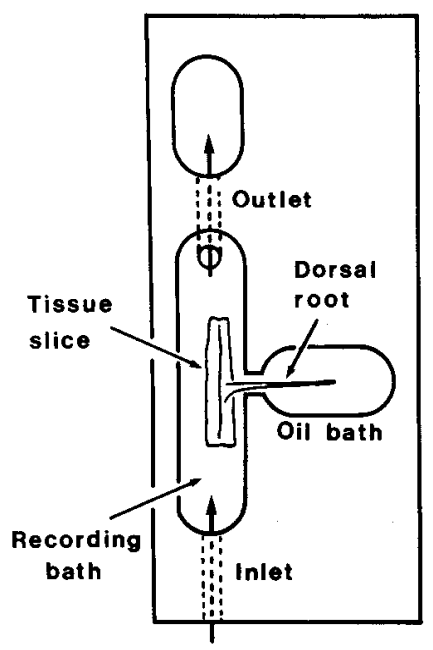

B

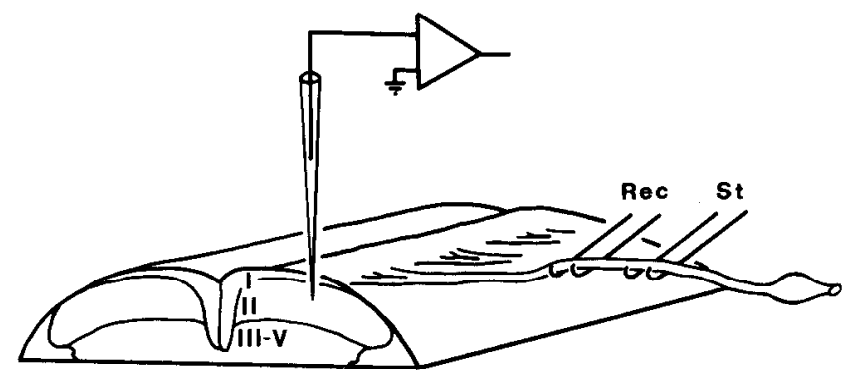

Figure 1. Experimental arrangement for in vitro dorsal horn slice. $A$, Recording chamber; $B$, positions of recording $(R e c)$ and stimulating $(S t)$ electrodes on dorsal root relative to tissue slice.
Synaptic activation of neurons in the preparation remained unchanged for $8-10 \mathrm{hr}$.

Electrical stimulation and intracellular recording. A pressor foot constructed from a specimen grid for electron microscopes was gently lowered onto the dorsal surface to improve mechanical stability. Microelectrode penetrations were made through the grid perpendicular to the pial surface at loci where field potentials evoked by dorsal root volleys were maximal (Fig. 1B). Intracellular recordings from single dorsal horn neurons and primary afferent fibers were obtained with fine-tipped, glass pipette electrodes (Brown and Flaming, 1977) filled with $3 \mathrm{M}$ potassium acetate or $2 \mathrm{M}$ potassium methylsulfate (DC resistance, $80-120 \mathrm{M} \Omega$ ). Signals were amplified by an electrometer system with bridge circuitry and stored on magnetic tape using an FM recording system. The microelectrode was advanced by a piezoelectric driver (a generous gift of Dr. A. R. Martin) attached to a stepping, hydraulic microdrive. Negative constant current pulses $20-50 \mathrm{msec}$ in duration and $0.5 \mathrm{nA}$ or less were injected through the recording pipette to measure neuronal input resistance.

Neurons were identified according to the measured distance from the point of contact with the dorsal surface of the spinal cord. We have shown by intracellular marking that, in these slice preparations of adolescent hamster spinal cords, this procedure localizes neurons within $50 \mu \mathrm{m}$ of loci marked by iontophoresis from recording electrodes (Schneider and Perl, 1985a). On this basis, recording locations were specified as the superficial dorsal horn (laminae I and II) or nucleus proprius (laminae III to V). This segregation was aided by recording of field potentials and the nature of excitatory drive from the dorsal root stimuli since the input to the superficial dorsal horn is dominated by excitation from thin primary afferent fibers, and there is a notable change in the field potentials and source of excitation between lamina II and the dorsal limits of the nucleus proprius (Christensen and Perl, 1970; Kumazawa and Perl, 1978; Light and Perl, 1979). The present observations were dominated by recordings from the superficial dorsal horn because of a specific emphasis on this region. Anatomical localization of recording sites with respect to individual spinal laminae was not attempted.

Volleys in dorsal root afferents were initiated by electrodes located about $8 \mathrm{~mm}$ from the spinal cord and were monitored by electrodes near the spinal cord junction (Fig. 1B). Components of the electrical signs of volleys reflecting synchronized activity in myelinated (A $\alpha \beta, \mathrm{A} \delta$ ) and unmyelinated $(\mathrm{C})$ fibers could be identified by waveform and by conduction velocity (calculated from latency and measured conduction distance to the monitoring electrode). Volleys in A $\alpha \beta$ fibers conducted between 7 and $25 \mathrm{~m} / \mathrm{sec}$, whereas those in A $\delta$ fibers conducted in the range of $2-5 \mathrm{~m} / \mathrm{sec}$. The velocity of C-fiber volleys was less than 1 $\mathrm{m} / \mathrm{sec}$. The conduction velocities of afferent fibers in this preparation were relatively low compared with in vivo observations in cat and primate (Burgess and Perl, 1973), reflecting the below-normal bath temperatures and species-related differences in axonal diameters and myelination. These conduction velocity values are comparable to those observed in young rats and guinea pigs (E. R. Perl, unpublished observations). Judgment about the relationship between the source of excitation to a neuron and the conduction velocity of afferent fibers was based upon a consistent correlation between a volley component and an intracellularly recorded synaptic potential.

Intracellular recordings from primary afferent fibers could be easily differentiated from postsynaptic discharges by a one impulse response to one stimulation of the dorsal roots at frequencies over $100 \mathrm{~Hz}$ with a near-constant latency (variation $<0.2$ msec) and by the absence of evoked or background synaptic potentials (see Fig. 4, D1-D3).

Drugs and solutions. Solutions were changed by switching between gravity-fed supply sources connected in parallel to the bath inflow tube. Synaptic transmission was blocked by changing to a modified ACSF with low $\mathrm{Ca}^{2+}(0.25 \mathrm{~mm})$ and high $\mathrm{Mg}^{2+}(5-10 \mathrm{~mm})$ at $\mathrm{pH} 7.4$ equilibrated with $95 \% \mathrm{O}_{2} / 5 \% \mathrm{CO}_{2}$ or to a Tris-buffered medium containing $\mathrm{Cd}^{2+}(0.1-1 \mathrm{mM})$ or $\mathrm{Mn}^{2+}(1-2.4 \mathrm{mM})$ at $\mathrm{pH} 7.4$ equilibrated with $100 \%$ $\mathrm{O}_{2}$ (Llinás and Sugimori, 1980). Application of excitatory amino acids via the bathing medium has been found to produce effects identical to those obtained with iontophoretic administration of the same agents (Schneider and Perl, 1985a). Solutions containing $N$-acetylaspartylglutamate (Bachem, Torrance, CA; Lot no. 948B), D,L-homocysteic acid (Sigma), kynurenic acid (Sigma), D- $\alpha$-aminoadipate (Sigma), D(-)-2amino-4-phosphonobutyric acid (Sigma), v(-)-2-amino-5-phosphonovaleric acid (Sigma), trans-free $( \pm$ )-cis-2,3-piperidine dicarboxylic acid (Cambridge Research Biochemicals), and $\gamma$-D-glutamylglycine (Cambridge Research Biochemicals) were prepared in ACSF immediately before use.

\section{Results}

\section{General characteristics of dorsal horn neurons in the sample}

Intracellular recordings for $30 \mathrm{~min}$ to over $3 \mathrm{hr}$ were obtained from 198 dorsal horn neurons. The mean resting membrane potential $\left(V_{M}\right)$ of the 147 neurons for which stable permanent records were available was $65.2 \pm 0.5$ (SE) $\mathrm{mV}$. The mean amplitude and duration of action potentials $(n=155)$ was $63.8 \pm$ $0.6 \mathrm{mV}$ and $1.9 \pm 0.1 \mathrm{msec}$, respectively; the values for neurons located superficially $(<200 \mu \mathrm{m}$ from the dorsal surface; $65.1 \pm$ $0.6 \mathrm{mV}, 2.0 \pm 0.1 \mathrm{msec})$ were essentially the same as for deeply located cells $(\geq 200 \mu \mathrm{m} ; 65.2 \pm 1.0 \mathrm{mV}, 1.5 \pm 0.1 \mathrm{msec})$. Thus, there was no evidence for a differential viability throughout the slice. Neuronal input resistance $\left(R_{N}\right)$ was quite variable, ranging in 132 cells from 1.5 to $208.6 \mathrm{M} \Omega$ (mean, $50.2 \pm 3.3$ ) suggesting a heterogeneous population in size and geometry. These values overlap somewhat but are generally lower than those reported by Murase and Randic (1983), also apparently derived from a 

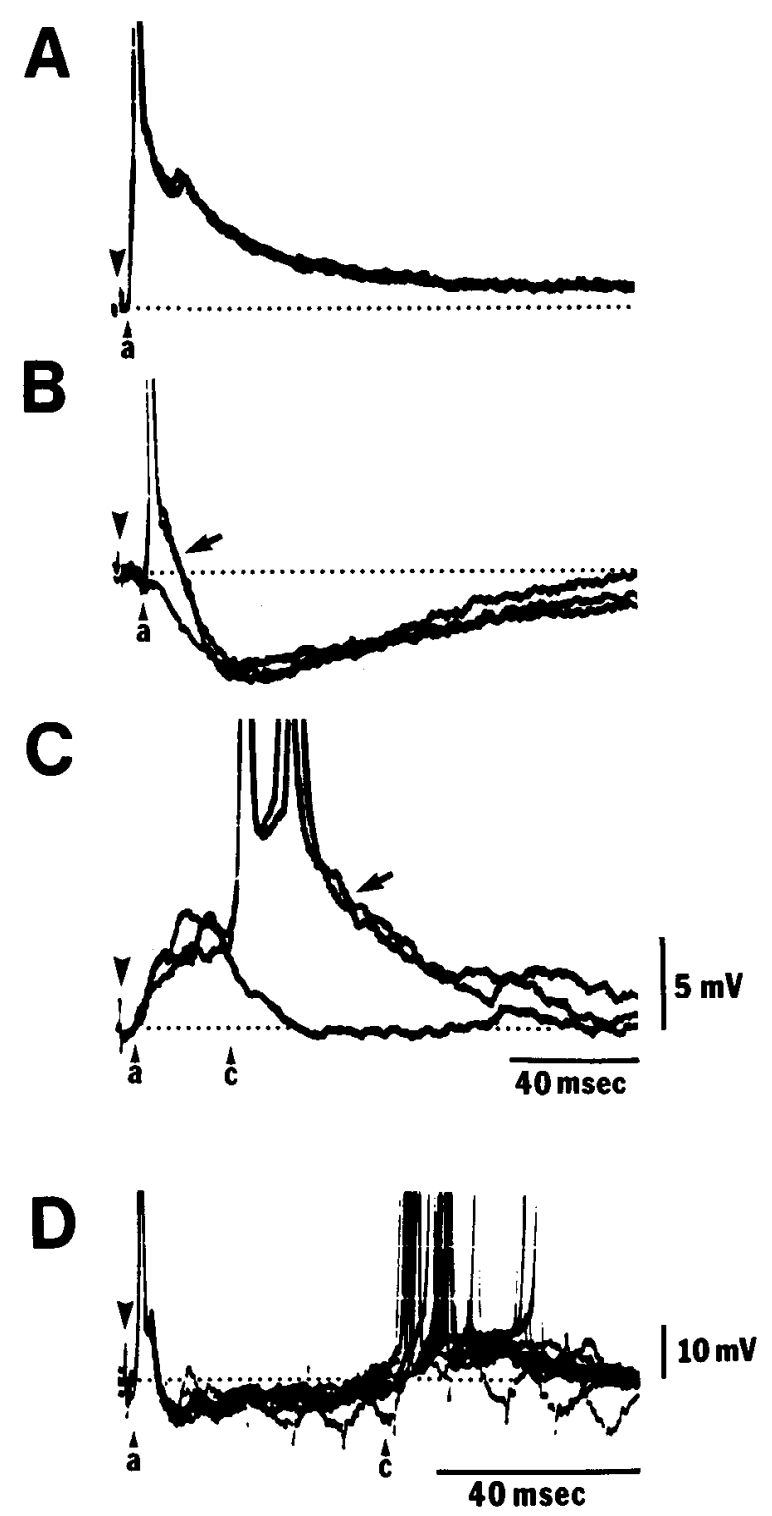

Figure 2. Intracellular recordings of dorsal horn neurons of the in vitro slice. Each display in $A-C$ is composed of 3 oscilloscope sweeps. Onsets of synaptic potentials activated by volleys in $\mathrm{A}$ - and $\mathrm{C}$-fibers are indicated at $a$ and $c$, respectively. $A$ and $B$, Two neurons responding only to myelinated $(A)$ afferent volleys. Neuron of $A$ was located in nucleus proprius $\left(V_{M}=-52 \mathrm{mV}\right)$. Neuron of $B$ was located in the superficial dorsal horn $\left(V_{M}=-63 \mathrm{mV}\right)$. $C$ and $D$, Two neurons responding to volleys in both A- and unmyelinated C-fibers. Neuron of $C$ was located in the superficial laminae $\left(V_{M}=-70 \mathrm{mV}\right)$. Arrows in $B$ and $C^{-}$mark 2 consecutive oscilloscope sweeps following afferent stimulation just suprathreshold for volleys in $A \delta-(B)$ and $C$ - $(C)$ fibers. $D$, Ten superimposed responses of a nucleus proprius neuron $\left(V_{M}=-62 \mathrm{mV}\right)$ to volleys in both A- and C-fibers. Hyperpolarization was present in the absence of spike discharge. Current ( $1 \mathrm{nA}$ ) pulses (downward) injected through the recording electrode, one pulse for each sweep at delays separated by duration of the pulse, indicate changes in $R_{N}$. Action potentials are truncated. Downward arrowheads mark stimulus artifact. Calibrations for $A$ and $B$ are shown in $C$.

mixed population of dorsal horn neurons from a horizontal slice preparation. $R_{N}$ of neurons $(56.8 \pm 4.0 \mathrm{M} \Omega, n=102)$ in the superficial dorsal horn $(<200 \mu \mathrm{m})$ was higher than those $(27.9 \pm$ $3.8 \mathrm{M} \Omega, n=30)$ in the nucleus proprius $(\geq 200 \mu \mathrm{m})$. Values for $R_{N}$ reported by North and Yoshimura (1984) for lamina II neurons in a transverse slice preparation are much higher than ours and Murase and Randic's (1983) from horizontal slices.
We have no evidence to account for this difference of $R_{N}$ from the observations on horizontal and on transverse slices; however, it may be significant that in all mammalian species the principal orientation of dendrites of superficial dorsal horn neurons is longitudinal, and these processes extend over distances often exceeding $500 \mu \mathrm{m}$. Some such processes surely would be transected in transverse slices $500 \mu \mathrm{m}$ thick used by North and Yoshimura (1984). Given the number of our recordings from depths and field potential zones corresponding to laminae I and II and the scarcity of large neurons in these levels, it appears unlikely that our sample was unduly biased toward large neurons.

Single dorsal root volleys initiated postsynaptic potentials (PSPs) in all neurons of the sample (Fig. 2). In most of these cells, volleys confined to myelinated (A) afferent fibers activated depolarizing excitatory postsynaptic potentials (EPSPs) with relatively invariant initial latencies $( \pm 0.2 \mathrm{msec})$. EPSPs were usually multiphasic with later components; the latter's usual relationship to stronger dorsal root stimulation suggested that the excitation involved more slowly conducting primary fibers and/ or more complex circuits. Since the earliest synaptic potentials, particularly in the superficial dorsal horn, were regularly associated in fibers conducting at less than the maximal in the stimulated dorsal root, proof of the number of synaptic links in the activation was impossible. This was particularly true for the later components of complex EPSPs. Nonetheless, it appeared likely on the basis of comparison with other systems (Kostyuk, 1961; Perl, 1962) that those dorsal root-initiated EPSPs with essentially invariant latencies were the result of simple, i.e., monosynaptic, linkages. The duration of EPSPs activated by A-fibers often increased with increasing stimulus intensity, depending on the composition of the volley, over a range of 7$100 \mathrm{msec}$. Volleys in A-fibers also activated hyperpolarizing, inhibitory postsynaptic potentials (IPSPs) in about $40 \%(71 /$ 181) of the sample (Fig. 2, $B, D$ ).

In some neurons, it was possible to distinguish between PSPs activated by rapidly $(\mathrm{A} \alpha \beta)$ and slowly $(\mathrm{A} \delta)$ conducting $\mathrm{A}$-fibers. PSPs initiated by $A \alpha \beta$ fibers (Fig. 2, $A, D$ ) occurred at a short latency $(2-4 \mathrm{msec})$ upon weak dorsal root stimulation conjointly with the A $\alpha \beta$ wave in the dorsal root volley (not shown). PSPs in other neurons (Fig. $2 B$ ) had a longer latency $(5-10 \mathrm{msec}$ ), typically required higher stimulus voltages than those with short latency, and were coupled to the appearance of the A $\delta$ deflection. Many short-latency and a number of longer-latency PSPs showed the stable latencies associated in other systems to be associated with monosynaptic activation.

C-fiber components were conjoint with EPSPs in about $40 \%$ $(77 / 196)$ of the population. Such EPSPs were defined as those appearing in parallel only with volleys containing activity in afferent fibers conducting at $<1 \mathrm{~m} / \mathrm{sec}$ and appearing at latencies consistent with the arrival of C-fiber input (15-50 msec). Examples are shown in Figure 2, $C$ and $D$. The C-fiber EPSPs had durations comparable to those initiated by A-fiber volleys (15$90 \mathrm{msec}$ ).

The PSPs evoked by single volleys in A- and/or C-fibers were associated with a decrease in $R_{N}$. (Fig. $2 D$, cf negative pulses early and late in sweep.) The decrease in $R_{N}$ contrasts with the increased $R_{N}$ of the much longer lasting potentials reported by Urban and Randic (1984) to be initiated in some dorsal horn neurons by repeatedly stimulating dorsal roots.

Transmembrane recordings from neurons excited by dorsal root volleys were obtained from 20 to $360 \mu \mathrm{m}$ ventral to the 


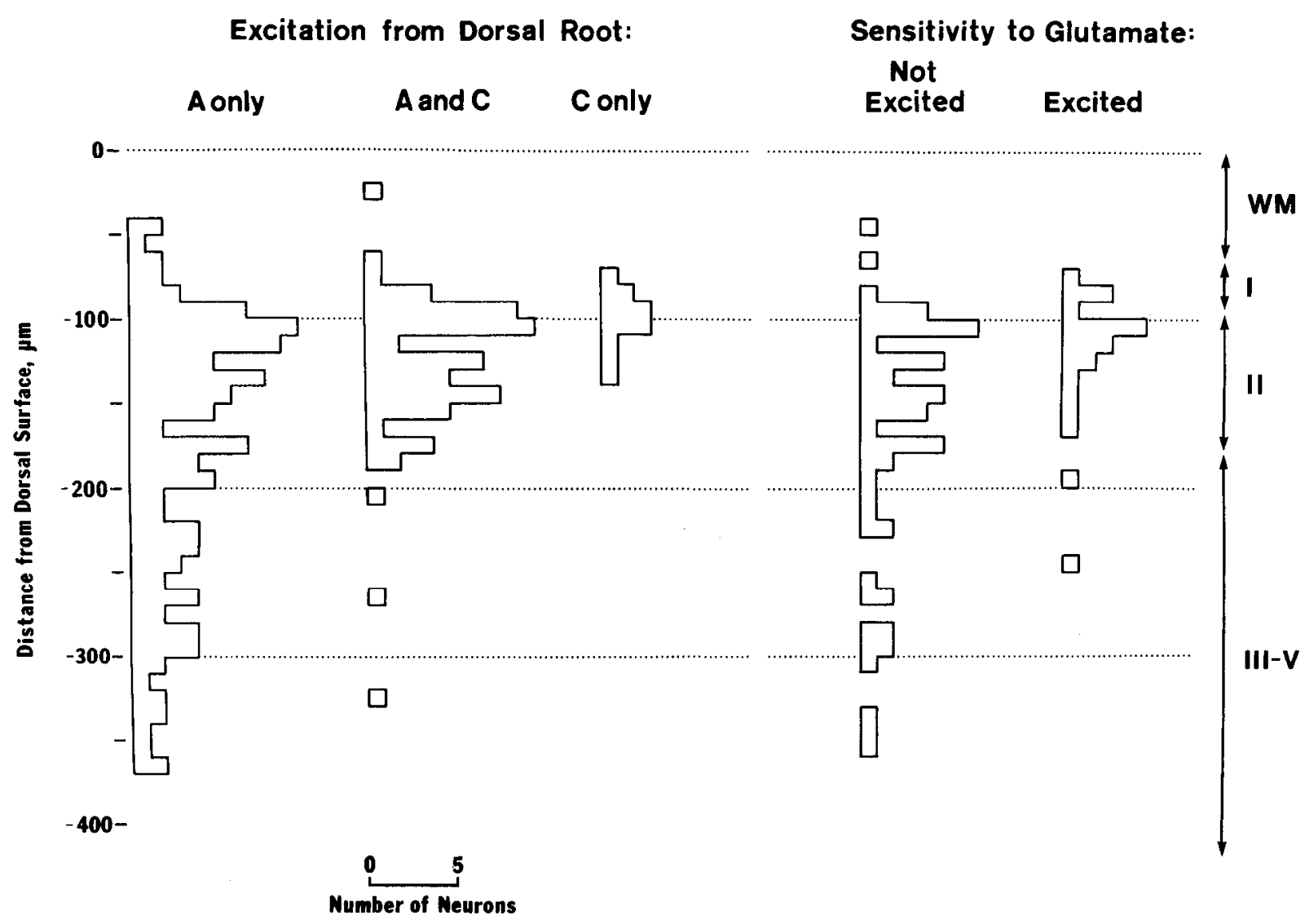

Figure 3. Location of neurons relative to the dorsal spinal surface related to excitatory components of the dorsal root volley $(A)$ and sensitivity to bath application of $1 \mathrm{~mm}$ L-glutamate $(B)$. Approximate boundaries of dorsal horn laminae are indicated at right. $I, I I, I I I-V$, Rexed's laminae; $W M$, white matter.

dorsal surface (laminae I-V). As shown in Figure $3 A$, neurons activated by $\mathrm{A}$ - and by $\mathrm{C}$-fiber components of the volleys were differentially distributed within the dorsal horn; this differential distribution was consistent with the termination pattern of thick and thin afferent fibers established in other species (Light and Perl, 1979). Neurons with EPSPs associated solely with the A-fiber component ("A only" in Fig. $3 A$ ) were located throughout the dorsal horn, whereas those exhibiting PSPs related to the C-fiber component ("C only," "A and C" in Fig. $3 A$ ) were most common $60-180 \mu \mathrm{m}$ bencath the dorsal surfacc.

\section{Effects of L-glutamate, L-aspartate and}

N-acetylaspartylglutamate ( $N A A G)$

L-glutamate, at bath concentrations of $1 \mathrm{~mm}$ or less, depolarized and initiated discharges in about $30 \%(22 / 77)$ of the dorsal horn neurons on which it was tested (Figs. $4 A 1,5 B, 6 A$ and $B, 8 A$ ). Seven neurons were hyperpolarized by L-glutamate. Two neurons were strongly excited by bath concentrations of L-glutamate of 50-100 $\mu \mathrm{M}$, but most excited cells required concentrations between 0.5 and $1 \mathrm{~mm}$ for marked depolarization and vigorous excitation. In the typical L-glutamate-sensitive neuron, increasing the concentration from threshold levels to $1 \mathrm{~mm}$ caused graded increases in the magnitude of the depolarization and the frequency of discharges, and sometimes induced a depolarization block of activity. The depolarization often occurred independently of an increase in spontaneous PSPs. Six neurons demonstrated strong excitation only at concentrations of $3 \mathrm{~mm}$ (Figs. $8 B$,9). L-Aspartate was tested in 10 neurons and showed effects identical to L-glutamate at the same concentrations (not shown). The depolarization produced by the highest concentration of L-glutamate tested upon 8 neurons averaged $17 \pm 3 \mathrm{mV}$ (4-29 $\mathrm{mV}$ ) and was associated with a substantial reduction in $R_{N}(52 \pm$ $7.5 \%$ ).

Fifty-five of the 77 dorsal horn neurons were judged insensitive to L-glutamate and/or I-aspartate because concentrations of $1 \mathrm{mM}$ or greater did not alter $V_{M}, R_{N}$, or frequency of discharge (Figs. $4 B, 11 A$ ). Concentrations of glutamate $1 \mathrm{~mm}$ in about $1 / 5$ $(8 / 43)$ of these L-glutamate-insensitive neurons induced a small, subthreshold depolarization $(4.0 \pm 0.9 \mathrm{mV})$ accompanied by a small reduction in $R_{N}(11 \pm 3 \%$, Figs. $4 C, 5 C, 11 B)$; increasing L-glutamate concentrations to $3 \mathrm{~mm}$ or more did not provoke responses in the insensitive group (Fig. 4B). A reduction in $R_{N}$ was never noted in the absence of changes in $V_{M}$. Neurons insensitive to L-glutamate were routinely recorded in the same preparation both superficially and more deeply than those excited by L-glutamate and had similar resting $V_{M}$ 's. Furthermore, 


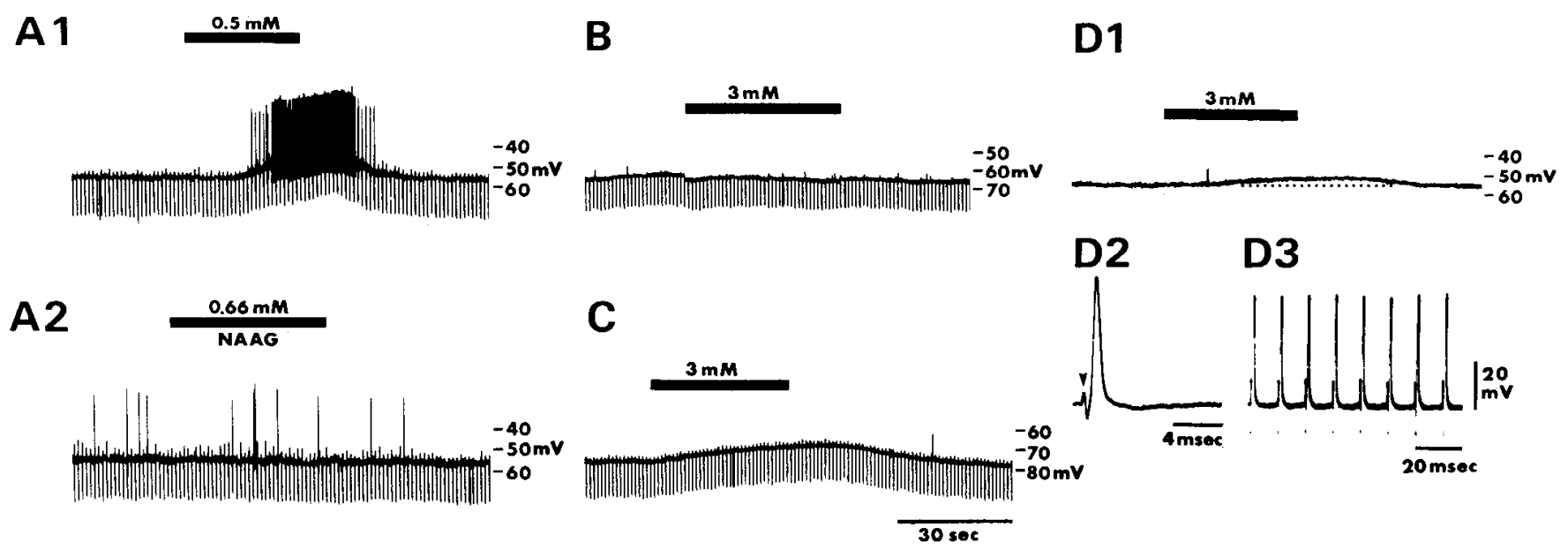

Figure 4. Effects of L-glutamate or like agents in superfusate on dorsal horn elements. Horizontal bars mark time of application of tested agent. $A 1$, L-Glutamate; $A 2, N$-acetylaspartylglutamate (NAAG) action on a superficial neuron; $B$ and $C$, two other superficial neurons. Calibration in $C$ for $A-C$. Action potentials are truncated by chart recorder. Downward deflections in the baseline represent intracellular current injection to measure $R_{N} . D$, Myelinated primary afferent fiber conducting at $11.4 \mathrm{~m} / \mathrm{sec} ; D 1$, L-glutamate; $D 2$, response to a single dorsal root volley; $D 3$, repetitive (100 $\mathrm{Hz}$ ) volleys. Downward arrowhead marks stimulus artifact.

the lack of sensitivity to L-glutamate appeared to be unrelated to the general condition of the preparation. In each of 4 instances, extracellularly recorded neurons that were unresponsive to L-glutamate were found to be strongly excited by bath application of $1 \mathrm{~mm}$ D,L-homocysteate. These observations indicate that insensitivity to L-glutamate is not the result of a general decrease in electrical signs of responsiveness.

At concentrations causing robust excitation in spinal neurons, L-glutamate neither excited myelinated primary afferent fibers nor altered their action potentials. This makes it unlikely that the excitatory effects observed in spinal neurons resulted from presynaptic actions on primary afferent terminals (see Curtis et al., 1984). High concentrations of L-glutamate ( $\geq 3 \mathrm{~mm}$ ), however, occasionally caused a small $(<4 \mathrm{mV})$ depolarization in primary afferent fibcrs (Fig. 4D1), suggesting that at such high glutamate concentrations, some type of presynaptic effect is possible.

NAAG, an acetylated dipeptide of aspartate and glutamate (Zaczek et al., 1983) has been reported to be present in DRG cells (Cangro et al., 1985b). The firing frequency, $V_{M}$, or $R_{N}$ (Fig. $4 A 2$ ) of 3 neurons strongly excited by L-glutamate and/or L-aspartate were not altered by synthetic NAAG at $1 \mathrm{~mm}$ concentration. Three other neurons that did not respond to $1 \mathrm{~mm}$ L-glutamate were also unresponsive to similar concentrations of NAAG.

\section{Characteristics of L-glutamate-sensitive neurons: laminar position, afferent input, and $\mathrm{R}_{\mathrm{N}}$}

The sensitivity of neurons to $\mathrm{L}$-glutamate was related to their dorsal-ventral location and to their $R_{N}$. Twenty-one neurons excited by L-glutamate at concentrations of $1 \mathrm{~mm}$ or less were concentrated in a zone between 70 and $170 \mu \mathrm{m}$ below the dorsal surface of the cord (Fig. $3 B$ ). This distribution is coextensive with that of neurons activated by volleys in C-fibers (Fig. $3 A$ ) and is contained in the superficial laminae of the spinal level from which the slice was prepared (Schneider and Perl, 1985a). Fifty-five neurons insensitive to L-glutamate were more uniformly dispersed throughout a zone that encompasses the bulk of the dorsal horn in the hamster (40-341 $\mu \mathrm{m}$ below the dorsal surface). Since in some cases, a deeper-lying neuron was found to be responsive to L-glutamate while superficial ones were not, skewing of the distribution of L-glutamate-insensitive neurons toward deeper locations in the slice is not simply due to differential drug diffusion. Moreover, arguments can be mounted that the cut deep surface of our type of slice may offer less of a barrier to diffusion than the pia-covered dorsal surfaces. The distribution of neurons excited by L-glutamate and those not excited is consistent with results from extracellular recordings (Schneider and Perl, 1985a), even though our present sample, biased by a deliberate effort to study neurons located superficially, resulted in a relative paucity of neurons more than $200 \mu \mathrm{m}$ from the dorsal surface (Fig. 3).

The relationship of the dorsal root valley components to EPSPs and $R_{N}$ to $\mathrm{L}$-glutamate and/or $\mathrm{L}$-aspartate responsiveness is summarized in Table 1 . No difference in the excitatory effectiveness of primary A- and C-fibers relative to L-glutamate responsiveness was apparent, possibly related to a sample bias toward neurons receiving excitatory input from A-fibers compared with our earlier survey of extracellularly recorded units (Schneider and Perl, 1985a). There was no difference in the proportion of neurons excited $(9 / 22)$ and not excited $(19 / 55)$ by L-glutamate which had EPSPs associated with C-fibers ("C only" and "A and C" in Table 1). On the other hand, the sensitivity of neurons to L-glutamate was correlated with their $R_{N}$ (Table 1); those excited by L-glutamate had a significantly $(p<0.001 ; t$ test, 2-tailed) greater $R_{N}(81.1 \pm 12.7 \mathrm{M} \Omega, n=15)$ than those unaffected by it $(47.5 \pm 4.8 \mathrm{M} \Omega, n=43)$.

\section{Effects of L-glutamate on spontaneous PSPS}

Subthreshold, transitory fluctuations in $V_{M}$ were evident in $63 \%$ $(55 / 88)$ of those neurons for which adequate records were available (Figs. $5 A, 10$ ). These events were similar in duration to EPSPs evoked by weak stimulation of the dorsal roots, varied in amplitude from 2 to $4 \mathrm{mV}$, and could be synchronized by volleys in the dorsal roots (not shown). Six neurons exhibited spontaneous hyperpolarizing PSPs, suggestive of spontaneous IPSPs, that could be synchronized by dorsal root volleys and reversed by injecting hyperpolarizing current through the re- 


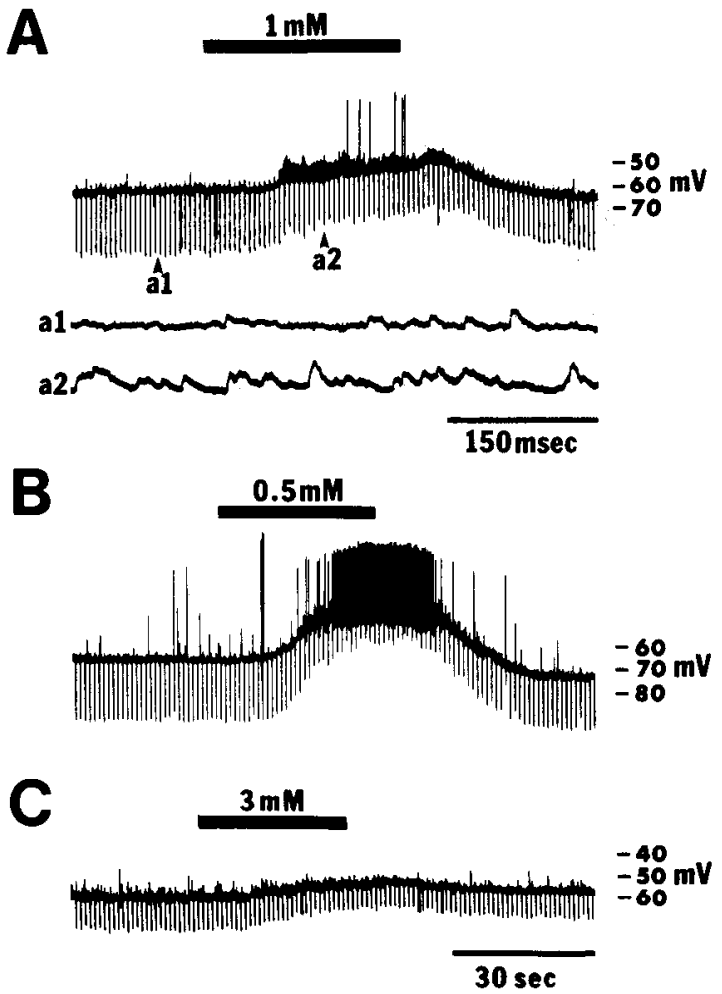

Figure 5. Action of L-glutamate on spontaneous EPSPs of 3 superficial dorsal horn neurons. $a 1$ and $a 2$ of $A$ are expanded oscilloscope sweeps showing EPSPs before and during presentation of L-glutamate, respectively. Calibration in $C$ applies to $A-C$.

cording pipette (not shown). This was taken as indicative of a reversal potential more negative than the recorded $V_{M}$.

Bath-applied L-glutamate $(0.5-1 \mathrm{~mm})$ increased the frequency of EPSP-like fluctuations for some L-glutamate-sensitive neurons $(13 / 30)$ coincident with the decreases in $V_{M}$ and $R_{N}$ and increase in discharge frequency (Fig. 5, $A$ and $B$ ). L-glutamate also increased the frequency of background EPSPs in a fraction of neurons $(16 / 57)$ that were otherwise unaffected by this compound (not shown). Elevating L-glutamate concentrations from 1 to $3 \mathrm{~mm}$ did not enhance this effect.

\section{Direct versus indirect effects of L-glutamate action}

An amino acid added to the superfusion fluid could act upon neurons synaptically linked to a cell under study, a possibility consistent with the observation that $\mathrm{L}$-glutamate often increased the frequency of background EPSPs. Superfusion with media containing low $\mathrm{Ca}^{2+}$ and high $\mathrm{Mg}^{2+}$ or with $\mathrm{Mn}^{2+}$ substituted for $\mathrm{Ca}^{2+}$ reversibly blocked the synaptic responses of neurons to dorsal root volleys (Fig. $6 A$, inset). Low-Ca ${ }^{2+}$ media also blocked L-glutamate-induced depolarization, background EPSPs, and the enhancement of L-glutamate upon background EPSP frequency in $52 \%(13 / 25)$ of tested neurons (Fig. $6 B$ ). The actions of low $\mathrm{Ca}^{2+}$ were manifested in 5-30 min and reversed within 10-45 min after return to the normal $\mathrm{Ca}^{2+}$ solution. Exposure to media with altered concentrations of divalent cations also reversibly reduced $R_{N}$ in some neurons (Fig. 6); this effect did not appear to be correlated with responsiveness to L-glutamate.

Superfusion with low $\mathrm{Ca}^{2+} /$ high $\mathrm{Mg}^{2+} \mathrm{ACSF}$ sufficient to completely block synaptic responses to dorsal root volleys either did not affect or only reduced the depolarization and excitation from
Table 1. Relationship of sensitivity to $1 \mathrm{~mm}$ L-glutamate to afferent volley composition and $\boldsymbol{R}_{N}$

\begin{tabular}{llllll} 
& \multicolumn{3}{l}{$\begin{array}{l}\text { Excitation from } \\
\text { dorsal root }\end{array}$} & \\
\cline { 2 - 5 } & A only C only C & $R_{N}$ \\
\hline $\begin{array}{l}\text { Excited by L-glutamate } \\
(n=22)\end{array}$ & 13 & 4 & 5 & $81.1 \pm 12.7$ \\
Not cxcitcd $(n=55)$ & 36 & 1 & 18 & $47.5 \pm 4.8$
\end{tabular}

Excitatory components of dorsal root volleys and $R_{N}$ for 77 dorsal horn neurons classified according to their sensitivity to L-glutamate. A only: neurons activated by dorsal root volleys containing only the $\mathrm{A}$ (myelinated) fiber component. $\mathrm{C}$ only: units activated only by volleys in $C$ (unmyelinated) fibers. $A$ and $C$ : neurons activated by volleys in both $\mathrm{A}$ and $\mathrm{C}$ fibers. $R_{v}$ : neuronal input resistance (mean \pm SEM)

L-glutamate (Fig. $6 A$ ) in about $50 \%(12 / 25)$ of L-glutamate-sensitive neurons. These observations led us to conclude that some of the dorsal horn neurons were excited by L-glutamate binding postsynaptically, while others were activated indirectly via action on presynaptic elements.

Four neurons that were unresponsive to L-glutamate (1 $\mathrm{mm})$ in normal ACSF were also unresponsive in low- $\mathrm{Ca}^{2+}$ media (not shown). Cells were never excited by superfusion of low $\mathrm{Ca}^{2+} /$ high $\mathrm{Mg}^{2+} \mathrm{ACSF}$ alone; therefore, the absence of excitatory response to L-glutamate appeared unlikely to have been the result of a masking by tonically released inhibitory transmitter action.

\section{Action of excitatory amino acid antagonists}

Excitatory amino acid receptor antagonists-kynurenic acid (Kyn), D- $\alpha$-aminoadipic acid (DAA), D(-)-2-amino-4-phosphonobutyric acid (APB), D(-)-2-amino-5-phosphonovaleric acid (APV), $\gamma$-D-glutamylglycine (DGG), and ( \pm )-cis-2,3-piperidine dicarboxylic acid (PDA)-differ in their antagonist properties. Kyn, APB, PDA, and DGG are believed to act at quisqualate, kainate, and $N$-methyl-D-aspartate (NMDA) subtypes of excitatory amino acid receptors, although their affinities for each subtype differ (Watkins and Evans, 1981; Perkins and Stone, 1982). DAA has its greatest affinity for the NMDA receptor but may also have actions at kainate receptors (Watkins and Evans, 1981). APV is the most selective of all the compounds; its actions are reported to be specific for the NMDA subtype (Watkins and Evans, 1981).

Dorsal root volleys evoke a complex that includes 3 negative waves $\left(\mathrm{N}_{1}, \mathrm{~N}_{2}\right.$, and $\left.\mathrm{N}_{\mathrm{C}}\right)$ in our in vitro preparation; these appeared comparable to those described in vivo in other species (Christensen and Perl, 1970; Beall et.al., 1977; Kumazawa and Perl, 1978) (Fig. 7A). The first wave, $\mathrm{N}_{1}$, with a peak at about $4 \mathrm{msec}$, was initiated by volleys limited to A $\alpha \beta$ fibers (Fig. 7Al) and was prominent throughout the thickness of the slice. The second, smaller wave, $\mathrm{N}_{2}$ (in monkey, $\mathrm{N}_{3}$ : Beall et al., 1977), with a peak at $9 \mathrm{msec}$, coincided with volleys in $A \delta$ fibers (Fig. $7 A 2$ ) and appeared largest when the tip of the recording electrode was between 50 and $150 \mu \mathrm{m}$ below the dorsal surface. This potential has been attributed to activity in neurons of the outermost superficial dorsal horn (Christensen and Perl, 1970). The third wave, $\mathrm{N}_{\mathrm{C}}$, with a peak at about $20 \mathrm{msec}$, was associated with volleys in $\mathrm{C}$-fibers (Fig. 7A3) and was concurrent with EPSPs in single neurons evoked by $\mathrm{C}$-fiber volleys. $\mathrm{N}_{\mathrm{C}}$ was most conspicuous when the tip of the recording electrode was located between 50 and $200 \mu \mathrm{m}$ below the dorsal surface. 
Figure 6. Effect of low $\mathrm{Ca}^{2+}$ on 2 superficial dorsal horn neurons. $A$ (same neuron as Fig. $4 A$ ), and $B . D R$, Response of each neuron to graded volleys in dorsal roots. $a$ and $c$, Synaptic response to volleys in A- and C-fibers, respectively. Bottom three rows: responses to L-glutamate in normal ACSF (control), in medium containing $1.3 \mathrm{mM} \mathrm{Mg}^{2+}$ and either $1 \mathrm{~mm}(A)$ or $2.4 \mathrm{~mm}(B) \mathrm{Mn}^{2+}$ (Ca-free) and after return to normal ACSF (wash). Insets in $A$ show effect of $\mathrm{Ca}$-free superfusate on response evoked by dorsal root stimulation at $\mathrm{C}$-fiber intensities (downward arrowheads). Effect of Ca-free medium on response of neuron in $B$ to dorsal root volleys same as in $A$ (not shown). Calibration for $A$ shown in $B$.
A $\quad$ B
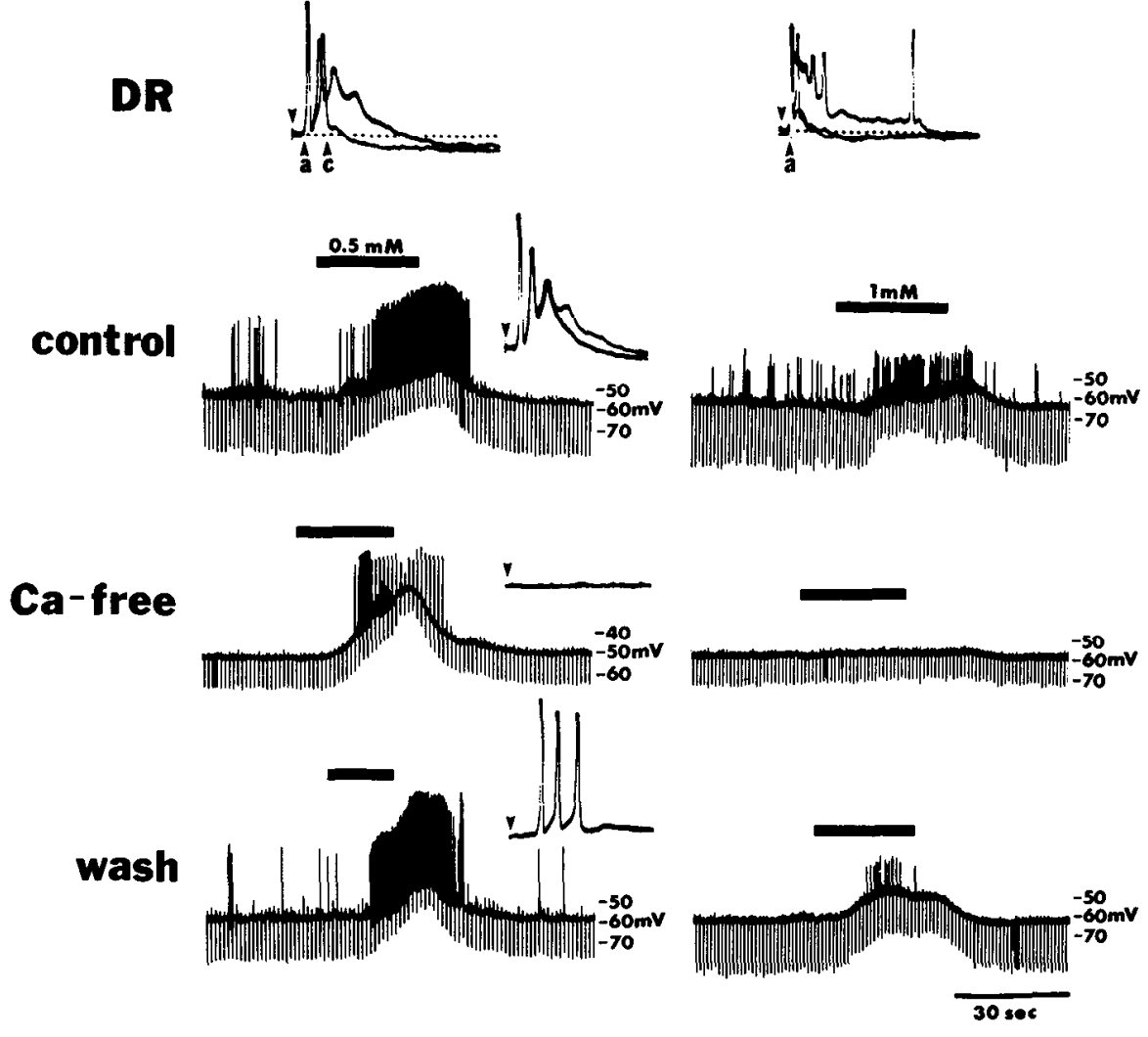

Kyn, APB, and PDA $(0.5,1 \mathrm{~mm})$ produced differential suppression of these 3 waves (Fig. $7 B$ ) in 5-10 min. Kyn ( $1 \mathrm{~mm}$ ) had only a small depressive action on the $N_{1}$ wave; in 9 experiments, this component was diminished by an average of only $12 \%$. In contrast, Kyn suppressed $\mathrm{N}_{2}$ and $\mathrm{N}_{\mathrm{C}}$ by more than $40 \%$. The effects of APB and PDA on the dorsal cord potentials were similar to those of Kyn. APV, DAA, and DGG had no effect at equivalent concentrations even when applied for $30 \mathrm{~min}$ (not shown). None of the compounds appeared to affect the amplitude, latency, or time course of the primary afferent volley.

Intracellularly recorded EPSPs initiated by dorsal root volleys were reversibly decreased in many $(21 / 35)$ of the neurons tested with $\mathrm{Kyn}(0.5,1 \mathrm{~mm})$ within 1-2 min after the beginning of superfusion, with the maximum effect occurring in 5-7 min. The number of action potentials evoked by a volley decreased, and discharges were sometimes abolished without changes in $V_{M}$ or $R_{N}$ (Table 2, Fig. 8). Longer exposure (up to $30 \mathrm{~min}$ ) to Kyn usually produced no further block. In 6 neurons, Kyn had little effect on IPSPs evoked by dorsal root volleys other than 2 instances in which the slope of the late phase of the afferentevoked IPSP was increased (see Fig. $8 A$ ). At concentrations up to $3 \mathrm{~mm}$ Kyn had no effect on resting $V_{M}$ spike duration, or conduction velocity of myelinated primary afferent fibers (not shown).

Kyn antagonized the responses of certain dorsal horn neurons to afferent input from both A- and C-fibers (see Table 2). Thirteen of 21 neurons whose dorsal root EPSPs were depressed by Kyn were synaptically activated only by volleys in A-fibers. Figure $8 A$ illustrates the effects of Kyn on a neuron in lamina
I or outer lamina II driven by volleys in A $\delta$ fibers. After superfusion for $4 \mathrm{~min}$ with $1 \mathrm{~mm}$ Kyn, the EPSP and action potential, but not the IPSP, were reversibly blocked. Eight of the 21 neurons received demonstrable excitatory input from $\mathrm{C}$-fibers. Kyn selectively antagonized responses to volleys in the $\mathrm{C}$-fibers but not the A-fibers in 3 neurons excited by both $\mathrm{A}$ - and $\mathrm{C}$-fibers. Figure $8 B$ shows an example of the effect of Kyn on a presumed lamina II or III neuron; superfusion of $1 \mathrm{mM} \mathrm{Kyn}$ for $1 \mathrm{~min}$ decreased the magnitude of the depolarization and reduced the number of discharges evoked by volleys in the C-fibers, while the earlier response to $\mathrm{A} \alpha \beta$ volleys was changed little. The blocking effects of Kyn were not related to a particular preparation. Neurons whose responses were partially or completely blocked were observed in preparations in which other neurons studied either before or afterward were unaffected.

These observations taken together indicated that the blockade was related to synaptic actions by a subset of myelinated or unmyelinated primary afferent fibers. The proportion of shorter latency responses evoked by dorsal root volleys in those dorsal horn neurons excited by L-glutamate differs from our earlier observations made on extracellularly recorded unitary potentials (Schneider and Perl, 1985a). One possible explanation for this discrepancy is a sampling bias in the selection of neurons for the present intracellular recordings, a selection that likely was biased to larger elements. However, even in the intracellular sample, the amino acid receptor blockade frequently selectively reduced EPSPs associated with thinner afferent fibers (A $\delta$ and C).

Nearly all neurons (19/21) whose synaptic activation from 
dorsal root stimulation was antagonized by Kyn were excited by bath application of L-glutamate (Figs. 8, 9). Excitation of most of these neurons $(12 / 14)$ by L-glutamate was reversibly antagonized in a concentration-dependent manner by pretreatment with Kyn media (Fig. 9, left). As shown in Figure 9 (right), the effect of Kyn on responses to L-glutamate paralleled the effect on the excitatory responses to dorsal root volleys.

In all of the 6 neurons that were excited by L-glutamate and for which appropriate observations were available, background EPSPs and synaptic excitation were blocked by Kyn at concentrations similar to that for L-glutamate excitation. For example, in Figure 10A, $0.5 \mathrm{~mm}$ Kyn reversibly blocked spontaneous EPSPs in a superficial laminae neuron $4 \mathrm{~min}$ after addition to the bathing medium. The suppression of background EPSPs (Fig. 10B) and the response to dorsal root stimulation (not shown) in the same neuron by APV were much less than that by Kyn.

In contrast to the marked effects described above, the responses of 14 of 35 neurons to dorsal root volleys were unaltered by $1 \mathrm{~mm}$ Kyn even when added to the superfusate for up to 30 min. In a few neurons, the only effect of Kyn was an increased variability in the latency to afferent stimulation. Neurons that were resistant to Kyn also tended to be unresponsive to L-glutamate; only 2 of 14 neurons were excited by L-glutamate at concentrations up to $3 \mathrm{~mm}$ (Table 2). Background EPSPs persisted in $1 \mathrm{~mm}$ Kyn in 4 neurons that were resistant to Kyn and insensitive to L-glutamate, although in 2 cases their amplitude and frequency were diminished.

Figure 11 illustrates the failure of Kyn to block the synaptic activation of 2 neurons receiving input from A-fibers. As shown in Figure $11 A$, Kyn had no effect on an EPSP and action potential evoked by vollcys in $\mathrm{A} \alpha \beta$ fibcrs in a nuclcus proprius ncuron but may have reversibly attenuated a small, later depolarization (arrows). The example in Figure $11 B$ also supports a differential action of Kyn on afferent fiber groups: Kyn had little effect on the synaptic response to volleys in A $\delta$ fibers of a neuron recorded in the superficial dorsal horn but reversibly diminished a small, later depolarization (arrows) related to C-fibers of the volley.

\section{Discussion}

A reevaluation of widely held views about the part played by L-glutamate-like agents and their membrane receptors for neurons in the spinal dorsal horn seems to be in order. First, our observations are inconsistent with the idea that L-glutamate is excitatory to all CNS neurons. In both the present and a previous sample (Schneider and Perl, 1985a), we found that marked somadendritic responsiveness to L-glutamate is limited to a subset (about a third) of dorsal horn neurons excited by primary af-

\section{A}

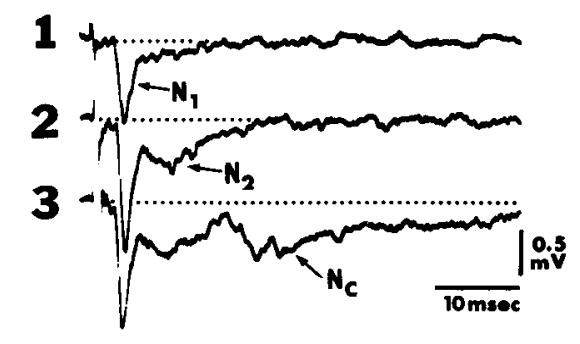

B
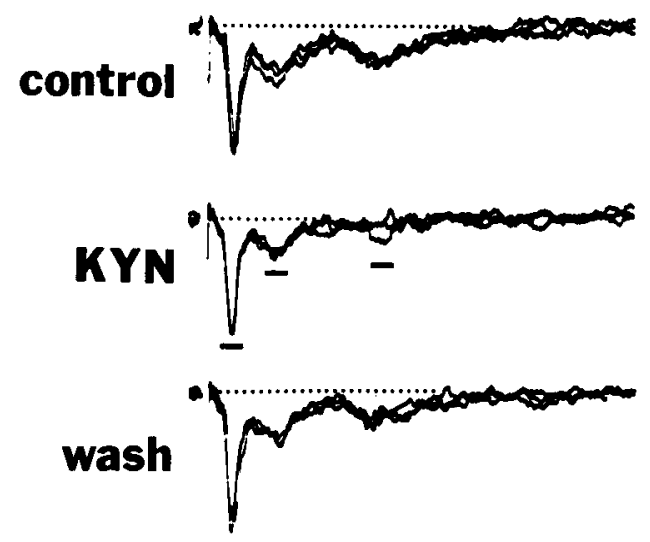

Figure 7. Action of excitatory amino acid antagonists on extracellular dorsal horn potentials. $A 1-A 3$, Single oscilloscope traces from recordings of activity in superficial dorsal horn evoked by dorsal root stimulation at $4.5,20$, and $75 \mathrm{~V}$, respectively. See text for significance of $N_{1}, N_{2}$, and $\mathrm{N}_{\mathrm{C}}, B$, Three superimposed oscilloscope sweeps of response to volleys containing $C$-fiber activity before (control), during $(K Y N)$, and after (wash) the addition of $0.5 \mathrm{~mm}$ kynurenic acid. Bars in $B$ indicate amplitude of potentials prior to KYN. Calibration for $B$ same as $A$.

ferent input, particularly those located in the superficial dorsal horn. These observations are consistent with the concept that for rapid synaptic transmission some, but by no means all, primary afferent fibers activate a postsynaptic membrane receptor responsive to L-glutamate agonists.

Given the similarity of recording sites, latency of effects and the sequential observation of responsive and unresponsive neurons in a given preparation, the large number of neurons unresponsive to L-glutamate in our preparations cannot readily be

Table 2. Relationship of kynurenate-induced antagonism of response to dorsal root stimulation to afferent volley composition and sensitivity to $1 \mathrm{~mm}$ L-glutamate

\begin{tabular}{|c|c|c|c|c|c|}
\hline & \multicolumn{3}{|c|}{ Excitation from dorsal root } & \multirow{2}{*}{$\begin{array}{l}\text { Excitation } \\
\text { by } \\
\text { L-glutamate }\end{array}$} & \multirow{2}{*}{$\begin{array}{l}\text { Antagonism } \\
\text { of } \\
\text { L-glutamate } \\
\text { excitation by } \\
\text { kynurenate }\end{array}$} \\
\hline & A only & C only & $A$ and $C$ & & \\
\hline Antagonized by kynurenate* $(n=21)$ & 13 & 5 & $3 \#$ & $19 / 21$ & $12 / 14$ \\
\hline Resistant to kynurenate ${ }^{* * *}(n=14)$ & 11 & 1 & 2 & $2 / 14$ & $1 / 1$ \\
\hline
\end{tabular}

\footnotetext{
* Response to dorsal root stimulation antagonized by $1 \mathrm{~mm}$ kynurenate.

** Response to dorsal root stimulation resistant to I mM kynurenate.

\# In the three neurons, kynurenate antagonized synaptic excitation by C-fibers.
} 
A
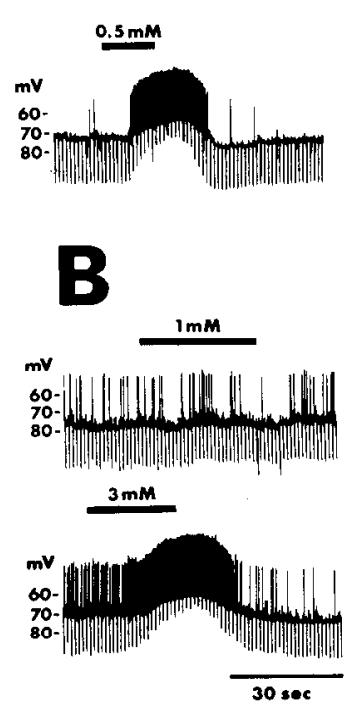

control
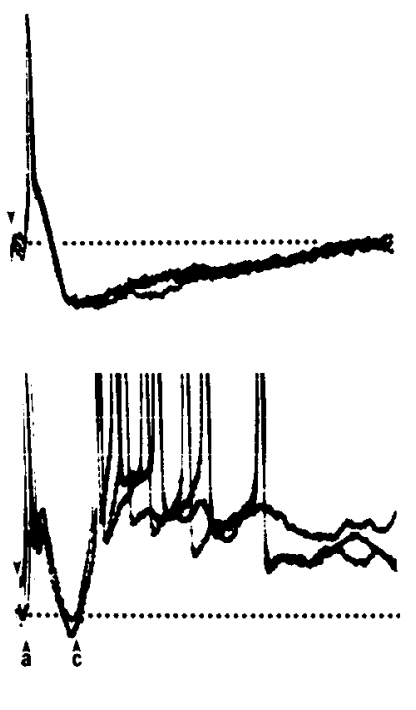

KYN
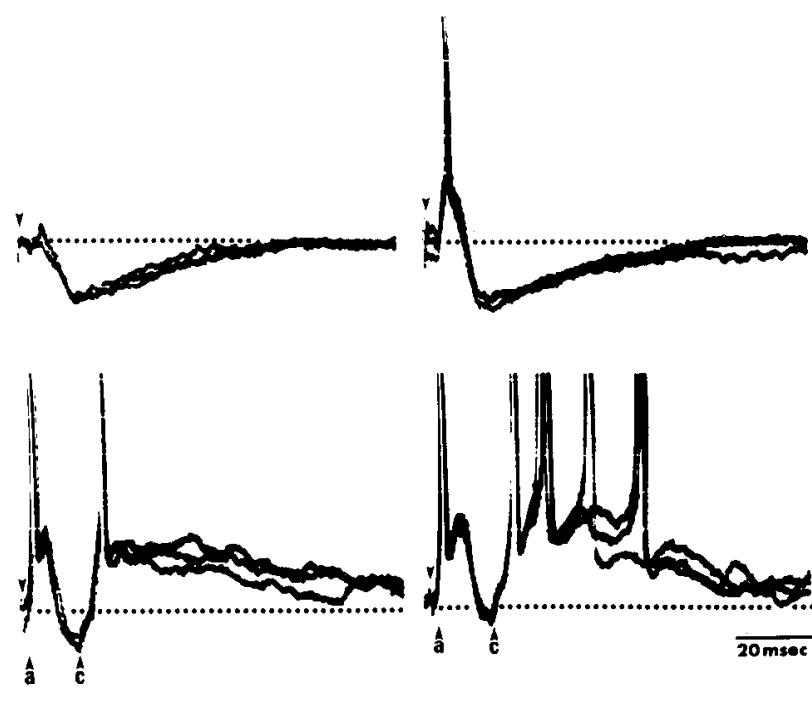

wash

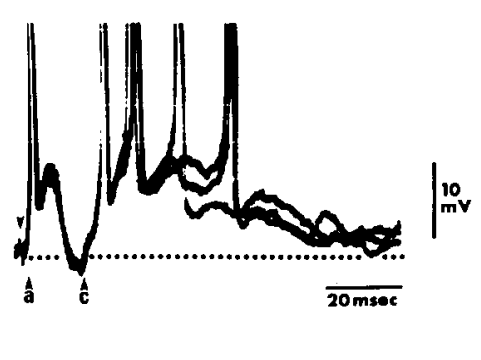

Figure 8. Effect of kynurenic acid $(K Y N)$ on intracellular responses to dorsal root volleys in L-glutamate-excited neurons. $A$, Superficial laminae neuron (same cell as Fig. $1 B$ ). B, Nucleus proprius neuron. Records at left show effects of L-glutamate application; remaining panels show 3 consecutive, superimposed oscilloscope traces of the responses to dorsal root stimulation volleys (downward arrowheads) before (control), during $(K Y N)$, and after (wash) the addition of $1 \mathrm{~mm}$ kynurenic acid to the bathing medium. $a$ and $c$, Same as in Figure 7. Calibrations in $B$ apply to $A$.

attributed to diffusion barriers to the ligands or by an unexplained inactivation of certain L-glutamate receptors. Glial uptake of L-glutamate (Shank and Aprison, 1981) also does not appear to be a reasonable explanation of these observations since L-glutamate-sensitive neurons were commonly located in the superficial dorsal horn where the processes of ependymal glial cells are in closest apposition with the somata of neurons (Scheibel and Scheibel, 1968).

The observed differences in responsiveness cannot be accounted for on the basis of either moderate differences in L-glutamate receptor numbers or differences in membrane resistance alone. Broad-spectrum amino acid antagonists like Kyn blocked

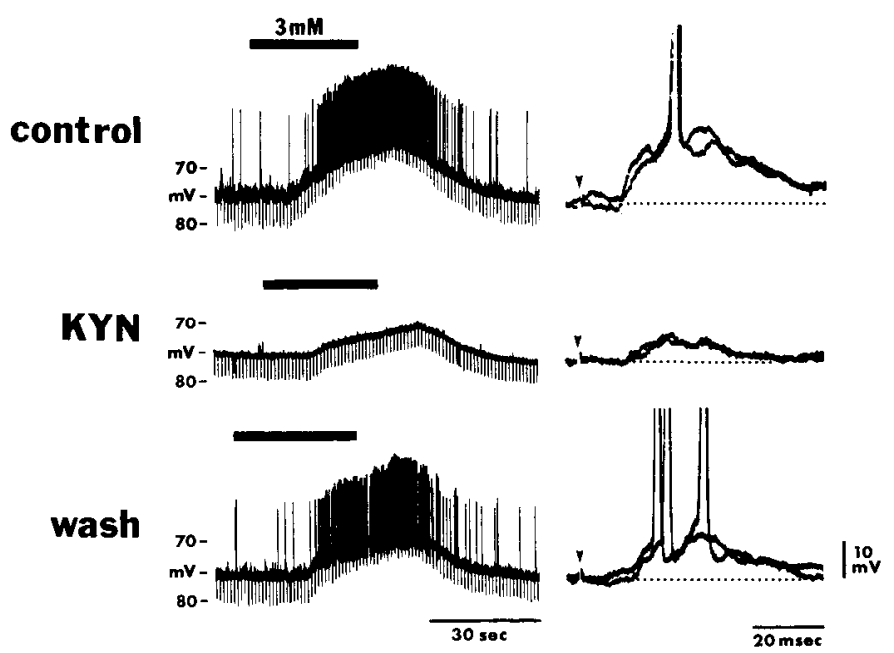

Figure 9. Responses of a superficial dorsal horn neuron to $3 \mathrm{~mm}$ L-glutamate (left) and to volleys in dorsal roots (right) before (control), during $(K Y N)$, and after (wash) bath application of $0.5 \mathrm{~mm}$ kynurenic acid. Stimulus artifact marked by downward arrowheads. Full amplitude of spikes not shown. or effectively interfered with synaptic activation evoked by dorsal root volleys in L-glutamate-sensitive neurons. Neither Kyn nor specific NMDA receptor blocking agents interfered with dorsal root excitation of neurons insensitive to L-glutamatc. This commonality in receptor properties for the synaptic and agonistinduced excitation is inconsistent with a purely quantitative difference in receptor or membrane properties. Nonetheless, on the average, neurons unresponsive to L-glutamate did have a lower $R_{N}$ than those excited by it. While differences in $R_{N}$ could reflect variations in neuronal size, in the number and branching of processes, or in specific membrane properties, measurements made in different cells can reflect varying combinations of these factors. Additional data are necessary to evaluate these possibilities; although given the high proportion of lamina I and II recording sites in the sample, it seems likely that the L-glutamate-responsive neurons were relatively smaller than the unresponsive ones. A parsimonious explanation for the selectivity of excitation is that only some dorsal horn neurons have depolarizing membrane receptors activated by L-glutamate.

\section{Mechanism of L-glutamate actions in vitro}

The L-glutamate effects on many neurons were probably generated by a direct interaction by the amino acid with a specific membrane receptor that opens ion channels and causes a decrease in $R_{N}$ and $V_{M}$ (reviewed by Jessell et al., 1986). Our principal evidence for such direct action is the continued excitation by L-glutamate after block of synaptic transmission in low $\mathrm{Ca}^{2+}$ and the antagonism of $\mathrm{L}$-glutamate-induced excitation by Kyn, a compound that interferes with all known subtypes of excitatory amino acid receptors. Excitation of other neurons by L-glutamate was $\mathrm{Ca}^{2+}$ dependent and thus may have been synaptically mediated, an interpretation consistent with the increase in frequency but not the amplitude of spontaneous EPSPs. However, this is equivocal evidence since amino acids can activate postsynaptic $\mathrm{Ca}^{2+}$ conductances that exist in dorsal horn 


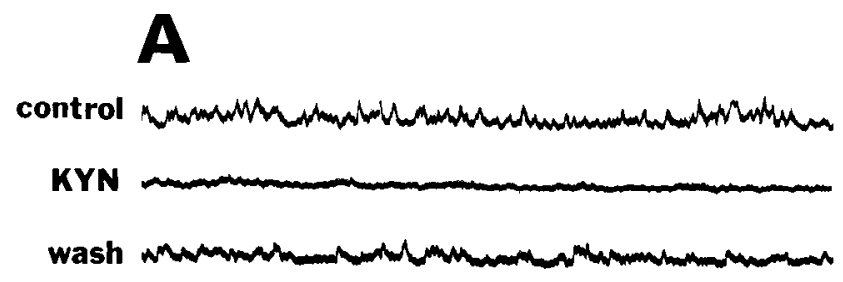

B

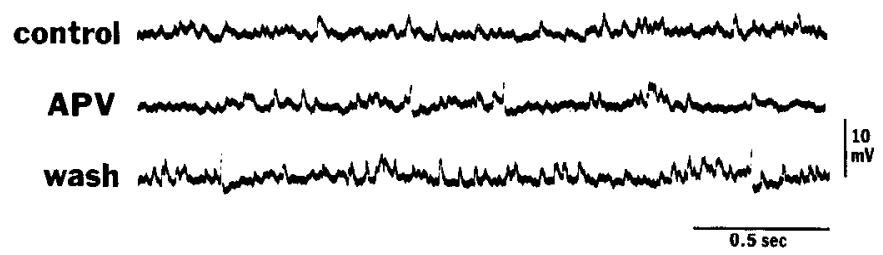

Figure 10. Spontaneous EPSPs in a neuron (same as for Fig. 9) before (control), during, and after (wash) exposure to $0.5 \mathrm{~mm}$ kynurenic acid $(K Y N, A)$ or $0.5 \mathrm{~mm} 2$-amino-5-phosphonovaleric acid $(A P V, B)$.

neurons (Dingledine, 1983; Murase and Randic, 1983; MacDermott et al., 1986).

Since it was not possible to establish the monosynaptic nature of afferent-croked EPSPs, the sites of action of agonist or antagonist compounds are uncertain. It is likely that some neurons were excited through interneurons by the actions of afferent volleys and L-glutamate. It also seems probable from the stability of the EPSP latency that some of the neurons both responsive and unresponsive to L-glutamate and Kyn were monosynaptically activated by primary afferent fibers. In any case, the observation that the afferent-evoked EPSPs of nearly all neurons insensitive to L-glutamate were resistant to Kyn sug- gests that some spinal afferent pathways do not employ the excitatory amino acids at either the first- or any higher-order synapses to the neurons we studied. Furthermore, the lack of striking effect upon afferent evoked-IPSPs by Kyn suggests that many inhibitory interneurons are driven by synaptic mechanisms other than those involving L-glutamate or its agonists.

Our studies do not make it clear which subtype(s) of excitatory amino acid receptors mediated the actions of $\mathrm{L}$-glutamate in the superficial dorsal horn. All these experiments were conducted in media with physiological concentrations of $\mathrm{Mg}^{3+}(1.5 \mathrm{~mm})$, lower concentrations of which have been shown to selectively block ion channels activated by the NMDA receptor (Ault et al., 1980; Mayer et al., 1984). It is reasonable to assume that under such conditions this receptor was effectively blocked, yet synaptic activation by primary afferent input was vigorous. The ineffectiveness of APV, DAA, and DGG, strong antagonists for the NMDA receptor, in blocking spontaneous EPSPs, responses to dorsal root volleys, and excitation by L-glutamate also suggest a lack of contribution by NMDA receptors to excitation observed in our preparation. Therefore, we support the proposition that excitatory L-glutamate actions stem from the kainate and/ or quisqualate types of receptors (Hill and Salt, 1982; Jessell et al., 1986).

\section{Transmission from primary afferent fibers}

The dipeptide NAAG has been described in somata of DRG cells (Cangro et al., 1985b) and reported to excite CNS neurons selectively (Bernstein et al., 1985; ffrench-Mullen et al., 1985). However, in our studies, NAAG had no apparent effect on $V_{M}$, $R_{N}$, or firing frequency of dorsal horn neurons. Therefore, NAAG does not appear to activate the excitatory receptors in this group of neurons.

The neurons excited by L-glutamate in the present study were concentrated in the superficial dorsal horn, corroborating our

\section{control}

\section{A}

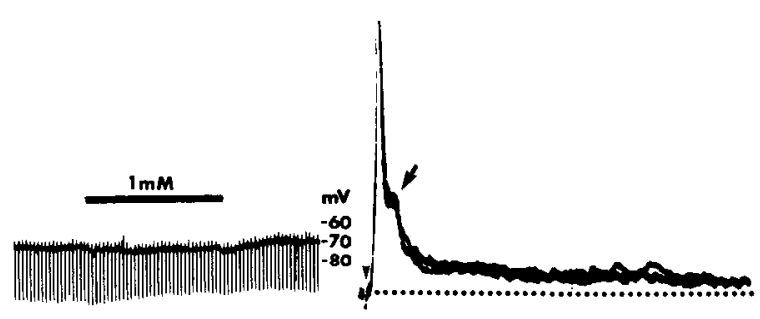

B

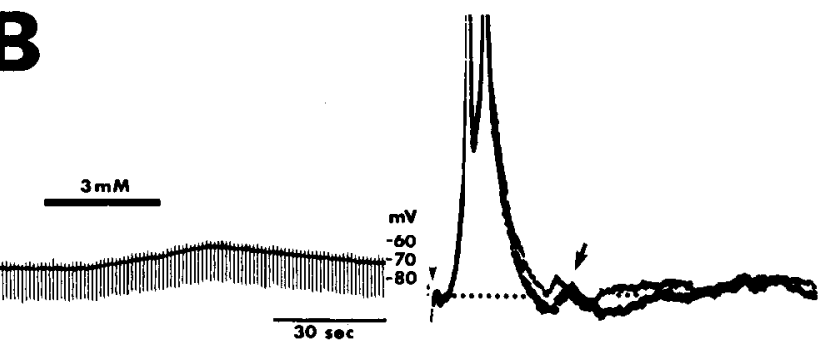

KYN
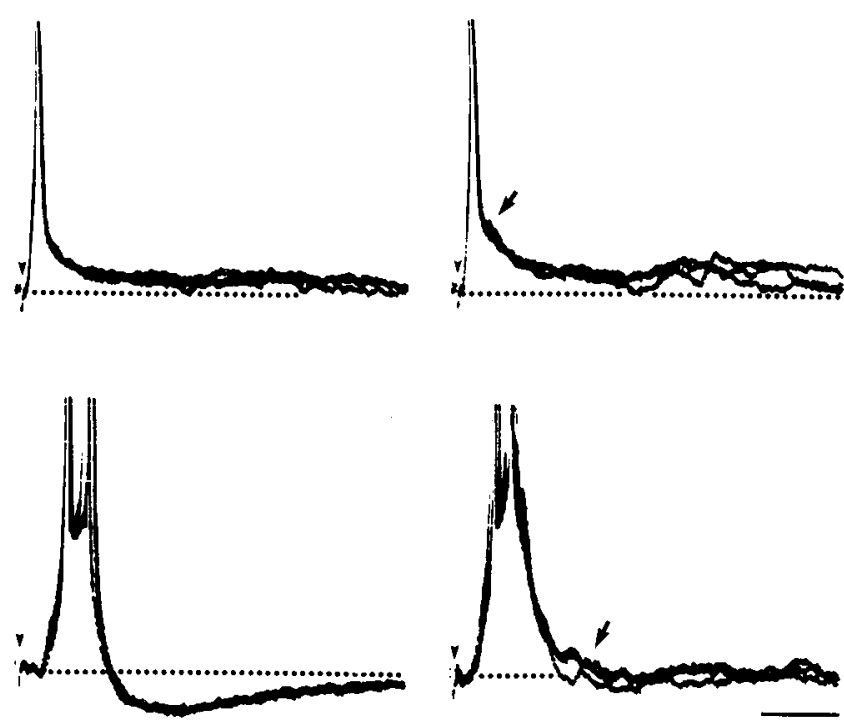

Figure 11. Effect of kynurenic acid $(K Y N)$ on responses to dorsal root stimulation for neurons unresponsive to $\mathrm{L}$-glutamate. $A$, Nucleus proprius neuron; $B$, superficial dorsal horn neuron. Arrows indicate components of synaptic response reversibly antagonized by KYN. Other details and abbreviations same as in Figure 9. 
observations on extracellularly recorded units (Schneider and Perl, 1985a). The superficial dorsal horn contains 3 to 4 times the number of receptors for ${ }^{3} \mathrm{H}$-L-glutamate exist in the ventral horn (Greenamyre et al., 1984). It has been reported that laminae I and II accumulate high levels of ${ }^{3} \mathrm{H}-\mathrm{D}$-aspartate (Rustioni and Cuenod, 1982; Hunt, 1983), a compound that has been postulated to be taken up by neurons using glutamate or aspartate as a neurotransmitter (Cuenod et al., 1981). Nerve tcrminals and some small neurons located in laminae I and II demonstrate a glutamate-like immunoreactivity (Van Eyck et al., 1986).

However, the superficial dorsal horn is not the only region of the CNS that receives input from primary afferent fibers and is associated with glutamatergic action. Jahr and Yoshioka (1986) recently showed that Kyn blocks the monosynaptic activation of motor neurons by Ia afferent fibers in vitro, supporting a longheld contention that large-diameter sensory axons are glutamatergic. Excitatory amino acids have also been implicated in transmitting impulses from low-threshold, cutaneous mechanoreceptors in the rat trigeminal nucleus (Hill and Salt, 1982).

The parallel action of Kyn on L-glutamate and dorsal root evoked excitation supports the hypothesis that an L-glutamatelike compound is responsible for the central synaptic excitation by a substantial number of primary afferent neurons with thin as well as thick afferent fibers (see also Perkins and Dray, 1986). In fact, in the dorsal horn, the greatest proportion of primary fibers exhibiting glutamatergic transmission appears in the smaller diameter population. On the other hand, our present as well as our past observations suggest that more than one-half of the fast EPSP generation by primary afferents in the dorsal horn involves other mediators and receptors.

\section{References}

Ault, B., R. H. Evans, A. A. Francis, D. J. Oakes, and J. C. Watkins (1980) Selective depression of excitatory amino acid induced depolarizations by magnesium ions in isolated spinal cord preparations. J. Physiol. (Lond.) 307: 413-428.

Bagust, J., I. D. Forsythe, G. A. Kerkut, and J. M. Loots (1982) Synaptic and nonsynaptic components of the dorsal horn potential in an isolated hamster spinal cord. Brain Res. 233: 186-194.

Balcar, V. J., and G. A. R. Johnston (1972) The structural specificity of the high affinity uptake of L-glutamate and L-aspartate by rat brain slices. J. Neurochem. 19: 2657-2666.

Beall, J. E., A. E. Applebaum, R. D. Foreman, and W. D. Willis (1977) Spinal cord potentials evoked by cutaneous afferents in the monkey. J. Neurophysiol. 40: 199-211.

Bernstein, J., R. S. Fisher, R. Zaczek, and J. Coyle (1985) Dipeptides of glutamate and aspartate may be endogenous neuroexcitants in the rat hippocampal slice. J Neurosci. 5: 1429-1433.

Brown, K. T., and D. G. Flaming (1977) New microelectrode techniques for intracellular work in small cells. Neuroscience $2: 813-827$.

Burgess, P. R., and E. R. Perl (1973) Cutaneous mechanoreceptors and nocireceptors. In Handbook of Sensory Physiology, Vol. 2, Somatosensory system, A. Iggo, ed., pp. 29-78, Springer-Verlag, Berlin.

Cangro, C. B., P. M. Sweetnam, J. R. Wrathall, W. B. Haser, N. P. Curthoys, and J. H. Neale (1985a) Localization of elevated glutaminase immunoreactivity in small DRG neurons. Brain Res. 336: 158-161.

Cangro, C. B., D. E. Garrison, P. A. Luongo, M. E. Truckenmiller, M. A. A. Namboodiri, and J. H. Neale (1985b) First immunohistochemical demonstration of $\mathrm{N}$-acetyl-aspartyl-glutamate in specific neurons. Soc. Neurosci. Abstr. 11(1): 108.

Christensen, B. N., and E. R. Perl (1970) Spinal neurons specifically excited by noxious or thermal stimuli: Marginal zone of the dorsal horn. J. Neurophysiol. 33: 293-307.

Cucnod, M., P. Bagnoli, A. Bcaudet, A. Rustioni, L. Wiklund, and P. Streit (1981) Transmitter specific retrograde labeling of neurons. In
Cytochemical Methods in Neuroanatomy, S. I.. Palay and V. ChanPalay, eds., pp. 17-44, Liss, New York.

Curtis, D. R., and G. A. R. Johnston (1974) Amino acid transmitters in the mammalian central nervous system. Ergebn. Physiol. 69: 97188

Curtis, D. R., J. W. Phillips, and J. C. Watkins (1960) The chemical excitation of spinal neurones by certain acidic amino acids. J. Physiol. (Lond.) 150: 656-682.

Curtis, D. R., P. M. Headley, and D. Lodge (1984) Depolarization of feline primary afferent fibres by acidic amino acids. J. Physiol. (Lond.) 351: 461-472.

Dingledine, R. (1983) N-methyl aspartate activates voltage-dependent calcium conductance in rat hippocampal pyramidal cells. J. Physiol. (Lond.) 343: 385-405.

Duce, I. R., and P. Keen (1983) Selective uptake of [ $\left.{ }^{3} \mathrm{H}\right]$ glutamine and $\left[{ }^{3} \mathrm{H}\right]$ glutamate into neurons and satellite cells of dorsal root ganglia in vitro. Neuroscience $8: 861-866$.

ffrench-Mullen, J. M. H., K. Koller, R. Zaczek, J. T. Coyle, N. Hori, and D. O. Carpenter (1985) N-acetylaspartylglutamate: Possible role as the neurotransmitter of the lateral olfactory tract. Proc. Natl. Acad. Sci. USA 82: 3897-3900.

Galindo, A., K. Krnjevic, and S. Schwartz (1977) Microiontophoretic studies on neurones in the cuneate nucleus. J. Physiol. (Lond.) 192: 359-377.

Graham, L. T., R. P. Shank, R. Werman, and M. H. Aprison (1967) Distribution of some synaptic transmitter suspects in cat spinal cord. J. Neurochem. 14: 465-472.

Greenamyre, J. T., A. B. Young, and J. B. Penny (1984) Quantitative autoradiographic distribution of $\mathrm{L}-\left[{ }^{3} \mathrm{H}\right]$ glutamate-binding sites in rat central nervous system. J. Neurosci. 4: 2133-2144.

Hill, R. G., and T. E. Salt (1982) An iontophoretic study of the responses of rat caudal trigeminal nucleus neurones to non-noxious mechanical sensory stimuli. J. Physiol. (Lond.) 327: 65-78.

Hunt, S. P. (1983) Cytochemistry of the spinal cord. In Chemical Neuroanatomy, P. C. Emson, ed., pp. 53-84, Raven, New York.

Jahr, C. E., and K. Yoshioka (1986) Ia afferent excitation of motoneurones in the in vitro new-born rat spinal cord is selectively antagonized by kynurenate. J. Physiol. (Lond.) 370: 515-530.

Jessell, T. M., K. Yoshioka, and C. E. Jahr (1986) Amino acid receptormediated transmission at primary afferent synapses in rat spinal cord. J. Exp. Biol. 124: 239-258.

Johnson, J. L., and M. H. Aprison (1970) The distribution of glutamic acid, a transmitter candidate, and other amino acids in the dorsal sensory neuron of the cat. Brain Res. 24: 285-292.

Kostyuk, P. G. (1961) Peculiarities of excitation and inhibition processes in single intermediate neurons of the spinal cord. J. Physiol. (USSR) 47: 1241-1252.

Kumazawa, T., and E. R. Perl (1978) Excitation of marginal and substantia gelatinosa neurons in the primate spinal cord: Indications of their place in dorsal horn functional organization. J. Comp. Neurol. 177: 417-434

Kvamme, E. (1983) Glutaminase (PAG). In Glutamine, Glutamate, and GABA in the Central Nervous System, pp. 51-67, Liss, New York.

Light, A. R., and E. R. Perl (1979) Reexamination of the dorsal horn projection to the spinal dorsal horn including observations on the differential termination of coarse and fine fibers. J. Comp. Neurol. 186: $117-132$

Llinás, R., and M. Sugimori (1980) Electrophysiological properties of in vitro Purkinje cell somata in mammalian cerebellar slices. J. Physiol. (Lond.) 305: 171-195.

MacDermott, A. B., M. L. Mayer, G. L. Westbrook, S. J. Smith, and J. L. Barker (1986) NMDA-receptor activation increases cytoplasmic calcium concentration in cultured spinal cord neurones. Nature 321: 519-522.

Mayer, M. L., G. L. Westbrook, and P. B. Guthrie (1984) Voltagedependent block by $\mathrm{Mg}^{2+}$ of NMDA responses in spinal cord neurones. Nature 309: 261-263.

Murase, K., and M. Randic (1983) Electrophysiological properties of rat spinal dorsal horn neurons in vitro: Calcium-dependent action potentials. J. Physiol. (Lond.) 334: 141-153.

North, R. A., and M. Yoshimura (1984) The actions of noradrenaline on neurones of the rat substantia gelatinosa in vitro. J. Physiol. (Lond.) 349: 43-55.

Perkins, M. N., and $\Lambda$. Dray (1986) Nociceptive activity in the neonatal rat spinal cord is antagonized by kynurenic acid and 2-amino- 
5-phospho-pentanoic acid (AP5). Soc. Neurosci. Abstr. 12(1): 55. Perkins, M. N., and T. W. Stone (1982) An iontophoretic investigation of the actions of convulsant kynurenines and their interaction with the cndogenous cxcitant quinolinic acid. Brain Res. 247: 184-187.

Perl, E. R. (1962) A comparison of monosynaptic and polysynaptic reflex responses from individual flexor motoneurones. J. Physiol. (Lond.) 164: 430-449.

Puil, E. (1981) S-glutamate: Its interactions with spinal neurons. Brain Res: Rev. 3: 229-322.

Roberts, P. J. (1974) The release of amino acids with proposed neurotransmitter function from the cuneate and gracile nuclei of the rat in vivo. Brain Res. 67: 419-428.

Rustioni, A., and M. Cuenod (1982) Selective retrograde transport of $\mathrm{D}$-aspartate in spinal interneurons and cortical neurons of rats. Brain Res. 236: 143-155.

Scheibel, M. E., and A. B. Scheibel (1968) Terminal axonal patterns in cat spinal cord. II. The dorsal horn. Brain Res. 9: 32-58.

Schneider, S. P., and E. R. Perl (1985a) Sclective cxcitation of ncurons in the mammalian spinal dorsal horn by aspartate and glutamate in vitro: Correlation with location and excitatory input. Brain Res. 360 : 339-343.

Schneider, S. P., and E. R. Perl (1985b) Kynurenic acid antagonizes synaptic and amino acid excitation of hamster spinal dorsal horn neurons in vitro. Soc. Neurosci. Abstr. 11(1): 217.

Shank, R. P., and M. H. Aprison (1981) Present status and significance of the glutamatc cycle in ncural tissucs. Life Sci. 28: 837-842.

Urban, L., and M. Randic (1984) Slow excitatory transmission in rat dorsal horn: Possible mediation by peptides. Brain Res. 290: 336341.

Van Eyck, S. L., R. J. Weinberg, F. Conti, P. Petrusz, and A. Rustioni (1986) Glutamate immunoreactivity in rat dorsal horn nuclei and substantia gelatinosa. Soc. Neurosci. Abstr. 12(1): 418.

Watkins, J. C., and R. H. Evans (1981) Excitatory amino acid transmitters. Annu. Rev. Pharmacol. Toxicol. 21: 165-204.

Zaczek, R., K. Koller, R. Cotter, D. Heller, and J. T. Coyle (1983) $\mathrm{N}$-acetylaspartylglutamate: An endogenous peptide with high affinity for a brain "glutamate" receptor. Proc. Natl. Acad. Sci. USA 80. 1116-1119.

Zieglgansberger, W., and A. Herz (1971) Changes of cutaneous receptive fields of spino-cervical-tract neurons and other dorsal horn neurons by microiontophoretically administered amino acids. Exp. Brain Res. 13: 111-126.

Zieglgansberger, W., and E. Puil (1973) Actions of glutamic acid on spinal neurones. Exp. Brain Res. 17: 35-49. 